
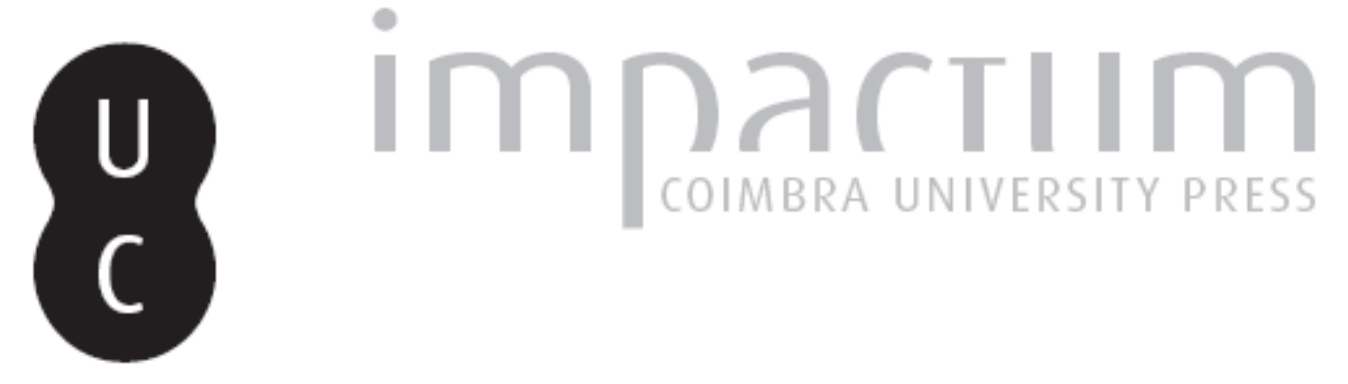

Obligaciones y relaciones de intercambio en el ámbito de la justicia penal

Autor(es): $\quad$ Sarrabayrouse Oliveira, María José

Publicado por: Universidade Católica de Petrópolis

URL persistente:

URI:http://hdl.handle.net/10316.2/33914

DOI:

DOI:http://dx.doi.org/10.14195/2175-0947_1-1_14

Accessed : $\quad$ 26-Apr-2023 13:29:14

A navegação consulta e descarregamento dos títulos inseridos nas Bibliotecas Digitais UC Digitalis, UC Pombalina e UC Impactum, pressupõem a aceitação plena e sem reservas dos Termos e Condições de Uso destas Bibliotecas Digitais, disponíveis em https://digitalis.uc.pt/pt-pt/termos.

Conforme exposto nos referidos Termos e Condições de Uso, o descarregamento de títulos de acesso restrito requer uma licença válida de autorização devendo o utilizador aceder ao(s) documento(s) a partir de um endereço de IP da instituição detentora da supramencionada licença.

Ao utilizador é apenas permitido o descarregamento para uso pessoal, pelo que o emprego do(s) título(s) descarregado(s) para outro fim, designadamente comercial, carece de autorização do respetivo autor ou editor da obra.

Na medida em que todas as obras da UC Digitalis se encontram protegidas pelo Código do Direito de Autor e Direitos Conexos e demais legislação aplicável, toda a cópia, parcial ou total, deste documento, nos casos em que é legalmente admitida, deverá conter ou fazer-se acompanhar por este aviso.

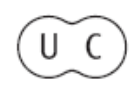



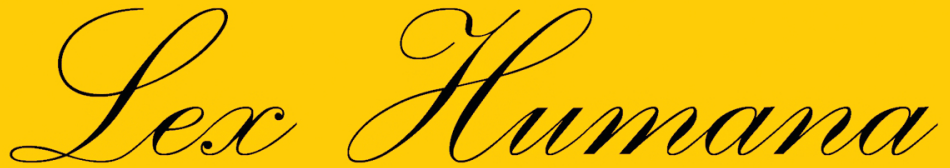

Revista do Programa de Pós-Graduação em Direito da UCP

ISSN(e) 2175-0947

Universidade Católica de Petrópolis Rua Benjamin Constant, 213 - Petrópolis - Centro CEP 25610-130

Tel: (24) 2244-4000 E-mail: lexhumana@ucp.br 


\title{
OBLIGACIONES Y RELACIONES DE INTERCAMBIQEN EL ÁMBITO DE LA JUSTICIA PENAL
}

\begin{abstract}
María José Sarrabayrouse Oliveira
Licenciada en Ciencias Antropológicas. Doutoranda em Ciencias Antropológicas - Faculdade de Filosofia e Letras, Universidad de Buenos Aires (UBA) Integrante da Equipe de Antropología Política e Jurídica. Instituto de Ciências Antropológicas. Faculdade de Filosofia e Letras. Universidad de Buenos Aires (UBA)
\end{abstract}

\section{Artículo}

Trabajos clásicos de la antropología han reconocido a las relaciones de intercambio como producto de obligaciones constitutivas de las relaciones sociales. Contra aquello que podría observarse desde una mirada superficial, las obligaciones, producto de las relaciones de intercambio, no atañen exclusivamente a las llamadas sociedades "primitivas" o propias de la antropología más tradicional, sino que se despliegan con toda su fuerza en espacios pertenecientes a las sociedades modernas en los que actúan como sostén de las relaciones sociales que allí se constituyen. A partir de este planteo inicial intentaré analizar un caso seleccionado que, en su calidad de extraordinario, permite entrever las relaciones que estructuran a la agencia judicial.

Hace ya varios años que estoy trabajando sobre el funcionamiento y las prácticas del poder judicial, particularmente en el ámbito de la justicia penal. El trabajo de campo desarrollado en este tiempo me ha permitido observar -al principio de un modo casi intuitivo- la importancia que poseen las relaciones de intercambio en el funcionamiento cotidiano de los agentes judiciales y el lugar fundamental que ocupan las obligaciones que las mismas acarrean. Poco se puede comprender sobre cómo se producen en la justicia los ingresos, los ascensos y el desarrollo cotidiano y rutinario de las relaciones entre los sujetos si no apelamos a las relaciones de intercambio. 
Esta "dificultad" en la comprensión puede llevarnos a caer en el error de una acusación moral que se centre en el "cómo deberían ser" las cosas y no en el conocimiento cabal del funcionamiento de la justicia penal.

En la tesis de doctorado que estoy realizando he planteado como objetivo general analizar el funcionamiento del poder judicial durante la última dictadura militar en la Argentina. Como parte de este trabajo he propuesto analizar la tramitación de algunas causas judiciales presentadas en aquellos años. Una de las causas seleccionadas es la que se conoció tanto en los pasillos de tribunales como en los organismos de derechos humanos como "causa de la morgue judicial", y su elección se debe -entre otros motivos- a que la misma presenta un hecho singular-desarrollado a lo largo de su tramitación- que permite focalizar en las obligaciones existentes entre los actores que integran el poder judicial ${ }^{1}$. El hecho al que hago referencia

$1 \quad$ Este expediente posee dos caras a ser analizadas. Por un lado, la causa se presenta como un caso excepcional en la medida en que queda en evidencia la colaboración de algunos burócratas judiciales con el terrorismo de estado. Asimismo, la actuación de los funcionarios judiciales -tanto en los hechos investigados como en la posterior tramitación del expediente-, permite develar la malla de relaciones sobre las que se estructuran sus prácticas. ( ) Por otra parte, en la causa también aparece lo que se podría denominar una punta de lanza de la investigación jurídica: un hecho que en líneas generales- representa lo cotidiano en los tribunales de aquellos años. Se trata de un expediente iniciado por privación ilegítima de la libertad donde se investiga la desaparición de un médico a fines de 1976, cuyo nombre era Norberto Gómez. Esta causa -como tantas otras- hubiese terminado arrumbada en el archivo de algún juzgado, si una cantidad de hechos fortuitos y no tanto- no hubiese ocurrido. Esto que denomino lo cotidiano permite reconstruir la trama administrativa de la violencia o, en otros términos, el crimen de oficina (Yan Thomas, 1999) ( ) Entiendo que lo excepcional y lo cotidiano no se deben visualizar como hechos antagónicos, sino que deben ser entendidos como fenómenos que se retroalimentan. En otras palabras, la causa de Gómez lo cotidiano- permitió llegar a la causa de la morgue lo excepcional-, y a partir de esta última 
es la presentación de las excusaciones ${ }^{2}$ realizadas por un conjunto de jueces al momento de intervenir en la causa en cuestión, donde lo que estaba en discusión era la actuación de varios de sus colegas con respecto a la complicidad en la utilización irregular, por parte de las fuerzas armadas, de las instalaciones de la morgue judicial ${ }^{3}$.

Las excusaciones presentadas en la causa de la morgue nos hablan de algo más que de figuras jurídicas. Son casos que permiten desentrañar la malla de relaciones sobre la que se sostiene la institución judicial y que permiten comprender con mayor profundidad el comportamiento de los individuos. En este sentido, podría incluir el caso que aquí voy a analizar entre los llamados "casos excepcionales, o los llamados casos contrarios [que] tienen la virtud de exponer a la luz aquello que permanece a la sombra en los análisis centrados sobre las normas y construidos por medio de modelos que, al no cuestionar aquello que en ellos no encaja, terminan por producir visiones simplificadas y empobrecidas del mundo social, como si su funcionamiento fuese simple y mecánico, como si en la realidad las cosas no fuesen fluidas, como insistían Max Weber y Edmund Leach (cf. Leach 1961; Weber 1965)" (Sigaud, 2004:133)4

se pusieron en evidencia todas esas relaciones sociales que hacen posible que esas prácticas cotidianas, burocráticas y asépticas condensadas en la causa de Norberto Gómez- tengan lugar. (Sarrabayrouse Oliveira, 2003:13-14)

$2 \quad$ La excusación es una figura jurídica a la que pueden apelar los funcionarios cuando consideran que no pueden actuar libremente en la tramitación y resolución de una causa debido a la existencia de una relación de parentesco, amistad, enemistad o de tipo económico con alguna de las partes implicadas. 3 Hacia 1976 los únicos juzgados que podían hacer uso de la morgue judicial sin tramitar ningún pedido específico ante la superioridad, eran los juzgados penales. Los que pertenecían a otros fueros debían realizar una solicitud especial para utilizar las instalaciones de la misma ante la Cámara del Crimen, la cual resolvía en un plenario -es decir, en una reunión extraordinaria en la que participan todos los integrantes de las distintas salas de la Cámara y donde resuelven situaciones de carácter administrativo o jurídico- si hacía o no, lugar al pedido. Demás está decir que ninguna otra oficina del estado podía hacer uso de la morgue sin la intervención del poder judicial con la consecuente iniciación de un expediente.

$4 \quad$ Sin lugar a dudas es necesario dar cuenta de la configuración sociohistórica (Sigaud, 2004: Elías, 1996) en el que está inserto este caso. Poco 
Así, en este artículo pretendo analizar las excusaciones presentadas por los distintos magistrados a la luz de la problemática de intercambio para, de esta manera, reconstruir no sólo los distintos tipos de relaciones existentes -que exceden claramente las de tipo funcional- sino los "bienes" que circulan así como los grupos que intervienen en los actos de intercambio. En otras palabras, poder analizar "más allá" de las normas jurídicas reconociendo la existencia de otras normas que están operando a la hora de analizar la conducta de los individuos. Como plantea Sigaud (1996), es necesario evitar el error de algunos cientistas sociales que "como si estuvieran contaminados por el sesgo de los juristas, tienden a aislar las conductas y a examinarlas preocupándose sólo por sus implicaciones en términos de cumplimiento o no cumplimiento de las normas jurídicas. Esto es lo que se observa, por ejemplo, en buena parte de los estudios sobre temas en boga relacionados con el derecho, como son los que toman por objeto la "violencia" o la "ciudadanía". Al proceder así no consiguen rescatar de forma positiva los comportamientos que están examinando y ni siquiera consiguen comprenderlos, sino sólo constatar que no se corresponden con lo que sería "deseable". Si lograsen asumir una postura de mayor distanciamiento con respecto a los "problemas sociales" que presenta la relación de los individuos con el cumplimiento de las normas jurídicas - que no son sino nada más que cuestiones prácticas para los interesados en el orden jurídico- podrían percibir que tales normas no poseen un mana ${ }^{5}$ que justifique por sí mismo el interés en que ser respetadas, y sobre todo, podrían identificar otras normas con las cuales los individuos de carne y hueso están vinculados en sus relaciones con otros individuos ${ }^{6}$ " podremos comprender si no consideramos la bisagra histórica que se estaba viviendo (el paso de una dictadura militar a un gobierno democrático) en articulación con las continuidades propias de la justicia (quién se va, quién se queda, qué favores se deben pagar y qué nuevas obligaciones se crearán) 5 La palabra mana es empleada aquí en el sentido de poder mágico, cualidad mágica, a partir del análisis de Mauss y Hubert sobre hechos de la Melanesia (1991: 101-115). Creer en el poder de las normas jurídicas no se distingue de la creencia en el poder de las cosas.

$6 \quad$ La dificultad de los cientistas sociales en asumir en sus análisis una posición de distanciamiento ante los problemas de las sociedades en las que viven son reales y provienen de su participación en los conflictos de su tiempo, como lo destacaba Elías (1993: 23-30). El efecto de la ausencia de distanciamiento se expresa en los temas que se escogen para estudiar-los temas "calientes"- y en las preguntas formuladas, que muchas veces no son más que preguntas del sentido común. Reconocer la existencia de tales dificultades es condición necesaria para 
(Sigaud,1996:2-3)

\section{El caso}

Los primeros pasos de la causa de la morgue

En noviembre de 1982 -faltando poco menos de un año para la caída de la última dictadura militar en la Argentina-, el Centro de Estudios Legales y Sociales (CELS) ${ }^{7}$ inició tanto una causa judicial ${ }^{8}$ como una presentación ante la Corte Suprema de Justicia de la Nación, en las que se solicitaba se investiguen las irregularidades advertidas en el funcionamiento de la Morgue Judicial entre los años 1976 y 1980 . En ambos escritos se denunciaba que la morgue judicial había efectuado autopsias, solicitado certificados de defunción al registro civil y realizado inhumaciones de cadáveres $\mathrm{NN}$ sin dar intervención al juez competente, sino a solicitud de las fuerzas armadas. De acuerdo a la información que poseía el CELS, las irregularidades habían ocurrido, por lo menos, con respecto a seis cadáveres pero "los elementos analizados (permitían) sospechar que tal procedimiento (había sucedido) en un mayor número de casos" (fs. 1vta.) y que, incluso, era una práctica habitual en el período aludido 9 .

A medida que la investigación judicial avanzaba -a pesar del contexto político en el que esto ocurría- comenzó a develarse la colaboración

poder, de alguna forma, controlarlas. Pero es preciso ir más allá e ejercer todo el tiempo una vigilancia redoblada sobre los problemas de estudio que se están construyendo y sobre los hechos que se están tomando para analizar.

$7 \quad$ Organismo de derechos humanos creado en 1979, en plena dictadura militar.

$8 \quad$ La causa judicial se inició tomando como una de las pruebas el expediente presentado a raíz de la desaparición, en 1976, de un médico llamado Norberto Gómez. En esa causa original existía un parte remitido por la Policía Federal en el que constaba que Gómez había fallecido en un "enfrentamiento" (eufemismo utilizado por las fuerzas armadas y de seguridad para referirse a los fusilamientos) y que su cadáver, junto con el de otros tres NN, había sido remitido a la morgue judicial "por orden de las fuerzas conjuntas" (fuerzas armadas) sin intervención del juez competente.

9 Algunos integrantes del CELS poseían esta información hacía ya varios años, sin embargo hasta el momento no se había presentado el momento político propicio que permitiese la tramitación efectiva del expediente. 
de diversos funcionarios judiciales para con las fuerzas armadas y empezó a extenderse un manto de sospecha sobre aquellos funcionarios y empleados que habían desempeñado tareas y habían firmado resoluciones durante aquellos años.

Claro ejemplo de este hecho es lo sucedido a comienzos de 1983 cuando los abogados del CELS presentaron, en nombre de los familiares de las víctimas, un recurso de apelación ante la Cámara en lo Criminal a fin de que resolviese su pedido para ejercer el rol como parte querellante ${ }^{10}$ en la causa ${ }^{11}$. Como la mayoría de los integrantes de la Cámara que debía resolver este conflicto, había desarrollado funciones en ese organismo entre el 24 de marzo de 1976 y diciembre de 1980, los abogados denunciantes decidieron recusar ${ }^{12}$ a los camaristas, argumentando que existían

[...] pruebas concretas de comunicaciones cursadas entre el Cuerpo Médico Forense y la Cámara del fuero donde fueron planteadas consultas relacionadas con la utilización del servicio de la Morgue que se venía efectuando en ese entonces por las Fuerzas Armadas (...) Con la documentación que oportunamente acompañáramos con nuestra denuncia, acreditamos que la Cámara tenía conocimiento de estos hechos irregulares (...) Este conocimiento de ilícitos y la participación de miembros y funcionarios de la Cámara lleva a la fundada sospecha sobre el conocimiento que de los mismos tenían todos los integrantes del cuerpo durante el período comprendido entre el 24 de marzo de 1976 y diciembre de 1980, quienes

10 El que acusa o reclama ante un juez o tribunal competente por violación de sus propios derechos.

11 Este pedido incluía una discusión tácita entre las partes acerca del tipo de delito que se estaba investigando: los denunciantes sostenían que el delito en cuestión era homicidio; los jueces, un delito de orden público, es decir que afectaba a la administración pública. De acuerdo a esta última posición, no era lógico que los familiares de Gómez se presentasen como querellantes. Es por ello que el CELS decidió apelar a la Cámara del Crimen para que resolviese la disputa. 12 Pedir el alejamiento de los jueces que intervienen en una causa por verse comprometidos con alguna de las partes. 
por acción u omisión, al no haberse opuesto a los hechos denunciados pueden tener interés en la causa. (Fs.26 vta.) ${ }^{13}$

Uno a uno, los miembros recusados del tribunal -en total eran veinte- fueron "inhibiéndose" de intervenir en la causa. Entre los que habían formado parte de la Cámara en los años en cuestión, algunos se excusaron mencionando, simplemente, que estaban comprendidos dentro de los términos de la recusación por haber sido designados como camaristas en aquella época; otros, manifestaron su abierta disconformidad con la presentación ya que alegaban "un total desconocimiento" -por aquellos añosde los hechos que se denunciaban.

Finalmente se conformó una sala con camaristas "no recusados", la cual resolvió aceptar como parte querellante a los familiares de las víctimas. De esta manera, habiendo transcurrido varios meses, la causa "volvió" a la primera instancia (el juzgado de instrucción) donde se estaba realizando la investigación. Sin embargo, para ese momento quien había sido titular de ese juzgado ya no se encontraba en su cargo y en su lugar había sido designado un nuevo juez, Fortich Baca. Ante el panorama anteriormente descrito, donde se comprometía ${ }^{14}$ y se pedía la recusación de una importante cantidad de funcionarios, el magistrado no encontró otro mejor camino que el de la excusación ${ }^{15}$.

13 También se presentó como sostén del pedido de recusación, una resolución de la Cámara del Crimen, que databa de octubre de 1977, en la cual los miembros de una de las salas declaraban la incompetencia de la justicia civil para intervenir en el caso de un detenido-desaparecido y derivaban el expediente a la justicia militar. Como parte de esta presentación se solicitó el nombre de los camaristas firmantes para que se los cite a prestar declaración indagatoria y para que, a su vez, se remitan los antecedentes de los mismos a la Corte Suprema de Justicia. Este caso -como tantos otros- permite descubrir y describir las prácticas judiciales que habitualmente llevaban a cabo los funcionarios tribunalicios durante la dictadura.

14 Mario Pena, presidente de la Cámara del Crimen entre 1976 y 1980, había sido procesado por las irregularidades ocurridas en la morgue judicial (la morgue judicial depende del Cuerpo Médico Forense el que a su vez depende de la Cámara del Crimen). Como ser verá en los próximos apartados, muchos de los magistrados estaban vinculados con Mario Pena por relaciones de distinta índole. 15 Cuando se presenta una excusación, el juez que se excusa debe presentar su resolución ante un nuevo magistrado (el que le sigue en orden de turno) el cual 
3. El largo camino de la excusación o la obligación de devolver. Dones y contradones

Entre los argumentos utilizados para fundamentar su alejamiento de la causa, el novel magistrado apeló -como sus colegas- a la amistad íntima que lo unía con algunos jueces sospechados, amistad que databa de sus inicios en la justicia, y a la "deuda" hacia quien había posibilitado su ingreso y progreso en la carrera judicial. No se trataba meramente de una relación funcional sino de un vínculo que atravesaba los más diversos ámbitos sociales, deportivos, académicos y familiares. Así decía Fortich Baca en su excusación:

[...] El ingreso del suscripto en la Justicia del Crimen como meritorio se produjo el 2 de octubre de 1969 en el juzgado de Sentencia letra "C", secretaría $\mathrm{N}^{\mathrm{o}} 6$, entonces a cargo del Dr. Néstor Nicolás Gómez, quien, más tarde, lo promueve en el escalafón administrativo en la Fiscalía $n^{\circ} 16$ de la que fue titular; finalmente, en noviembre de 1982, el proveyente es designado Secretario de la Sala III del Excma. Cámara, integrada también por le Dr. Gómez (...) Así, además de la amistad ya existente entre el Dr. Gómez y familiares del declarante -desempeñábase desde tiempo atrás en la secretaría $\mathrm{n}^{\circ} 6$ el hermano de mi padre-, se forjó a través de esa dilatada relación funcional una amistad que puedo calificar como íntima, en los términos del art. 75 , inc. $12^{\circ}$, del Código de Procedimientos en materia penal, además de lo cual existe de parte de quien ahora debe decidir el natural agradecimiento hacia quien posibilitó en gran medida su progreso en la carrera judicial (...) Respecto del Dr. Mario H. Pena existe, además, concreta imputación en el dictamen producido por

puede seguir distintos caminos: rechazar la excusación y hacer que vuelva al juez original; aceptarla y tomar la causa o aceptarla pero excusarse de intervenir y derivarla a otro juez. 
el Dr. Severo Caballero ante la Corte Suprema de Justicia de la Nación, recogida en la resolución del Alto Tribunal que en su consecuencia se dictó (...) En cuanto a dicho magistrado, la relación amistosa y cordial que me une proviene, trascendiendo el marco de lo estrictamente funcional, de la conformación de un grupo de camaradería por ambos integrado, que semanalmente se reúne con fines sociales y deportivos, además de la íntima existente y su hijo Héctor, con quien compartiera en su oportunidad el honor de desempeñarse como Secretarios del Juzgado de Instrucción $n^{\circ} 14$, del Dr. Oscar Mario R. Ocampo, y aún hoy pertenecen ambos a la cátedra de Derecho Penal parte especial del Dr. Spolansky, en la Universidad de Belgrano (fs.937 vta.)

El juez que recibió esta primera excusación - Mugaburu- le hizo lugar, y paso seguido presentó la propia. En ella sostenía su alejamiento de la causa aduciendo que:

[...] entre esos magistrados se encuentra el Dr. Néstor N. Gómez, por intermedio de quien logré ingresar en la Justicia de Instrucción en el año 1971; el Dr. Miguel Angel Almeyra, actual titular de la Cátedra de Derecho Procesal en la que me desempeño como profesor adjunto; el Dr. Vicente E. Andereggen, de quien soy discípulo en razón de haber sido alumno suyo mientras cursé el bachillerato (1964), pudiéndolo mencionar asimismo como una de las personas que despertaron en mí la vocación por el derecho; el Dr. Julio C. Ledesma, con quien compartí durante varios años, la cátedra universitaria; el Dr. Carlos Guardia, con quien me une una relación de amistad. Destaco asimismo que durante años he tenido trato frecuente a través de la actividad judicial (...) con la mayoría de los afectados, entre 
los que señalo [enumera una larga lista] algunos de los cuales fueron mis superiores jerárquicos (...) Por último menciono al Dr. Miguel Ángel Madariaga, quien siendo titular de la cátedra de derecho procesal penal en la UBA me honró al proponerme como adjunto, siendo la persona que el día de mi juramento como magistrado me puso en posesión del cargo" (Causa penal 40.357/82, fs. 1051-1051vta.)

Longobardi fue el tercer juez que recibió la causa y -como sus antecesores- la rechazó, presentando una nueva excusación:

[...] entre los imputados a quienes está dirigida esta acción, se encuentran magistrados y ex magistrados con los cuales el proveyente mantiene y ha mantenido vínculos de amistad íntima y de frecuencia de trato [...] Tal es el caso del Dr. Mario H. Pena, a quien me une una amistad íntima, prolongada e ininterrumpida desde el año 1956 [...] Asimismo, con el Dr. Carlos Alberto Tavares, me une una relación de amistad y frecuente trato desde hace veinticinco años aproximadamente, lapso en el cual pude seguir toda su carrera en el Poder Judicial quien además en algunos momentos y cuando más lo necesitaba, me brindó su apoyo espiritual [...] Por último con el Dr. Raúl Noailles, si bien no me une un vínculo estrecho de amistad, existe un trato frecuente y muy cordial por ser colega de la Facultad de Derecho y Ciencias Sociales de la Universidad Nacional de Buenos Aires $y$, cuando se desempeñaba el proveyente como funcionario de la Caja Nacional de Ahorro y Seguro, en varias oportunidades hube de gestionarle la obtención de préstamos personales [...] Todo lo expuesto precedentemente crea en el ánimo del suscripto un grado de violencia moral que me lleva a considerar el apartamiento de esta 
causa por las causales de excusación (Causa penal $40.357 / 82$, fs. $1057-1057$ vta.)

Siguiendo con el mismo procedimiento, la excusación de Longobardi fue aceptada por Lafitte quien a su vez también se inhibió de actuar en la causa en cuestión:

[...] con los Dres. Miguel Ángel Almeyra y Guillermo Rivarola me une una larga amistad que data desde comienzos de la década de 1960 en la que fuimos compañeros de trabajo en el fuero federal, vínculo que nos ha unido desde entonces, existiendo gran familiaridad y frecuencia de trato, lo que se ha visto fortalecido con el transcurso del tiempo. Lo dicho se halla ratificado por las públicas manifestaciones vertidas por el Dr. Almeyra, laudatorias y de profundo cariño hacia mi persona, en ocasión de ponerme en posesión del cargo que detento, respondiendo a la invitación que le formulara, para que fuera él, por las circunstancias de amistad, antedichas, que presidiera tal ceremonia (Causa penal 40.357/82, fs. 1060-1060vta.)

El quinto y último juez en intervenir en la "carrera excusatoria" fue Oliveri, quien distanciándose del proceder de sus colegas rechazó la excusación y redactó una resolución en la que daba cuenta de todas estas relaciones -que parecen estar enfrentadas con el mundo de las prácticas y normativas jurídicas- pero, marcando una diferencia con sus predecesores, las rechazó como argumento para la no intervención en el expediente judicial:

También resulta notoria la homogeneidad de los argumentos esgrimidos por los excusados, conformantes de una verdadera "familia judicial", fruto de una imbricada red de relaciones funcionales y -mayoritariamente- extrajudiciales que liga a las magistrados y ex magistrados del fuero, desde los más antiguos camaristas 
hasta los flamantes colegas del suscripto (...) Quienes hemos pasado buena parte de nuestra existencia labrando en el azaroso servicio de la administración de justicia, nos conocemos -en mayor o menor medida- y es razonable predicar sobre la atmósfera de cordialidad subyacente en cada saludo, en cada encuentro casual y -aún- en ocasión de enfrentar asuntos judiciales conexos. ¿Quién no ha estrechado alguna vez la mano de otros funcionarios o magistrados del fuero, o se ha sentado junto a ellos en una cena de camaradería, o - por el contrario- ha resultado sancionado por cuestiones de superintendencia? [...] Mas no parece atinado concluir que esa interferencia de conductas inhabilite para el conocimiento y decisión de un caso en el que aparezca implicado otro miembro del Poder Judicial, aunque perteneciere al mismo fuero que el del juzgador" (Causa penal 40.357/82, fs. $1063 / 1064$ )

La resolución de Oliveri culminó con un rechazo de la excusación de Lafitte, quien apeló la decisión ante la Cámara del Crimen. Finalmente y luego de varias presentaciones de los distintos funcionarios judiciales como de la querella -que no hacen al interés en este trabajo- la causa quedó en manos del último juez, Oliveri.

\section{Obligaciones y valores morales}

Toda relación social conlleva obligaciones, es decir, deberes que los individuos sienten poseer en su relación con otros individuos. La existencia y el cumplimiento de estas obligaciones sociales vinculan a los individuos entre sí. 
La vida social implica una permanente circulación de $\operatorname{cosas}^{16}$ (Mauss, 1979; Sigaud, 2004). Como planteaba Mauss en su clásico "Ensayo sobre el don", “(...) lo que se intercambia no son exclusivamente bienes o riquezas, muebles e inmuebles, cosas útiles económicamente; son sobre todo gentilezas, festines, ritos, servicios militares, mujeres, niños, danzas, ferias en las que el mercado ocupa sólo uno de los términos de un contrato mucho más general y permanente" (1979:160). Las personas participan de un constante intercambio y al hacerlo están obligados a cumplir con determinadas pautas. Por ello y considerando que el intercambio constituye la punta del iceberg de las relaciones sociales, a las cuales expresa, es que podemos decir que el intercambio interesa más por lo que muestra del mundo social que por lo que es en sí. En otras palabras, al hablar de intercambio nos importa ver quiénes intervienen, qué es lo que se da, qué es lo que se devuelve.

Por eso, el análisis de las excusaciones permite poner en foco las obligaciones que son producto de las relaciones establecidas entre los miembros del poder judicial. Relaciones sociales que, como se dijo anteriormente, se expresan en el intercambio. Pero para ello debemos ir más allá de lo que la reglamentación y la normativa dicen, romper con el constreñimiento propio de aquellas miradas que tienden a aislar las conductas de los individuos, limitándose a indagar si las mismas se condicen o no con la regla. Más allá de las prohibiciones que puedan surgir de la normativa jurídica, si analizamos los comportamientos a la luz del marco más amplio de relaciones sociales en el que están insertos los actores, podremos observar que determinadas conductas sólo se explican por la existencia previa de relaciones (sostenidas en el intercambio) que atrapan a los individuos en un circuito de deudas y favores, donde valores como la gratitud y la lealtad dan cuenta de las obligaciones que se deben cumplir so pena de romper la relación $^{17}$.

Las excusaciones presentadas por los distintos jueces se sostienen recurriendo al argumento de la existencia de determinadas relaciones que -

16 “(...) todo, alimentos, mujeres, niños, bienes, talismanes, tierra, trabajo, servicios, oficios, sacerdotales y rango son materia de transmisión y rendición. Todo va y viene como si existiera un cambio constante entre los clanes y los individuos de una materia espiritual que comprende las cosas y los hombres, repartidos entre las diversas categorías, sexos y generaciones" (Mauss, 1979:170171)

17 Faltar a las obligaciones es señal de que algo está sucediendo en ese vínculo. En una situación extrema esto puede implicar la ruptura de la relación. 
según lo planteado por los actores en el marco de la lógica jurídica- deberían mantenerse al margen de las relaciones funcionales. Las relaciones en cuestión abarcan un amplio espectro que incluye la amistad -propia o de familiares- ("me une una amistad íntima, prolongada e ininterrumpida desde el año 1956"); el parentesco; la conformación de grupos de camaradería ("semanalmente se reúne con fines sociales y deportivos"); el compañerismo surgido por el desempeño laboral tanto en el poder judicial como en la universidad ("con quien compartiera en su oportunidad el honor de desempeñarse como Secretarios del Juzgado de Instrucción $\mathrm{n}^{\mathrm{o}} 14$, del Dr. Oscar Mario R. Ocampo, y aún hoy pertenecen ambos a la cátedra de Derecho Penal parte especial del Dr. Spolansky, en la Universidad de Belgrano”); la subordinación ("algunos de los cuales fueron mis superiores jerárquicos (refiriéndose a los funcionarios imputados)". Conforme el supuesto desde el que parto para la elaboración de este artículo, estas relaciones que según la normativa jurídica deben mantenerse apartadas del desempeño funcional de los individuos, ${ }^{18}$ constituyen -en realidad- la malla sobre la que se configura el poder judicial ${ }^{19}$. Paradójicamente, es mediante la denuncia de la existencia de estas relaciones "prohibidas" que los actores implicados defienden la continuidad de las mismas.

Pero para comprender el interés que presentan los individuos en la continuación de estas relaciones es necesario conocer -mínimamente- cómo es el modo de incorporación de los agentes al poder judicial ${ }^{20}$.

El ingreso a tribunales, el comienzo de la denominada "carrera judicial" implica -la mayoría de las veces- el pedido de designación de una persona -generalmente un estudiante de derecho- ${ }^{21}$ por parte de algún 18 Estas relaciones son fuertemente negadas, ocultadas o disimuladas por los miembros de la justicia. Permanentemente parecen necesitar, para un eficaz desempeño, de la simulación de una distancia que por la práctica misma se hace casi imposible. Así lo decía en una entrevista una jueza de un tribunal oral: “(...) está muy incorporado al personaje tribunalicio que cuando hay una persona de «afuera»-aunque te tutees con el superior-, para dar la imagen de respeto o algo por el estilo, delante de una persona ajena, no lo tuteas (...) es muy natural que pase eso, casi como que pertenece a la forma de trabajo" (Juez Tribunal Oral) $19 \quad \mathrm{Al}$ menos en el caso de Argentina.

20 Sobre los modos de ingreso y el reclutamiento de agentes en la justicia ver Sarrabayrouse Oliveira (2004)

21 El primer escalón en lo que se conoce como la "carrera judicial" es el cargo de meritorio. Este cargo no consta en el escalafón administrativo y, por 
familiar o conocido o -en ciertos casos- el ingreso a partir del patrocinio de algún profesor de la facultad de derecho. Este pedido original puede ser parte de un circuito de intercambios preexistente o puede inaugurar uno nuevo, en otras palabras, puede reforzar lazos sociales preexistentes o crear nuevos:

Mi tío entró de pinche a Tribunales. Después del último pinche, no lo conocía nadie. Pero bueno, un vecino, un conocido de la familia cuando se enteró que iba a estudiar derecho le preguntó si quería entrar a trabajar en Tribunales, y con la carrera le venía bien y encima eran unos mangos porque no tenían plata...estaban en Pampa y la vía; de manera que empezó a estudiar y empezó a trabajar. Fue haciendo su carrera en Tribunales...Se recibió, primero fue secretario, después fue juez...Fue fiscal también, por cierto. Entonces, fue secretario, fue fiscal, después fue juez de sentencia en el A -en el juzgado A- y después lo ascendieron a la Cámara [...] Cuando él era camarista, uno de sus secretarios había ascendido a juez y se le produjo un interinato, una vacante interna -un empleado que se fue con licencia por una beca, qué sé yo- y yo estaba estudiando derecho, yo estaba bastante avanzada en la carrera. Entonces él me preguntó si yo tenía ganas de trabajar en Tribunales (!). Yo le dije que sí (!), además, viste, me interesaba por la práctica...Entonces entré como interina, seis meses. Y después la vacante se produjo efectiva y me quedé, por supuesto (!). De ahí hasta aquí." (Jueza de Tribunal Oral).

Al decir de Mauss, el don instituye una doble relación entre el que dona y el que recibe: por un lado, una relación de solidaridad en la medida en que el acto de compartir aproxima a las personas, por el otro, una relación lo tanto, no se trata de una función remunerada. Como lo indica la palabra, el meritorio debe hacer mérito para lograr un lugar como empleado "oficial" en el poder judicial. 
de superioridad, ya que aquél que recibe un don contrae en ese mismo acto una deuda con quien donó, convirtiéndose el primero en deudor del segundo. Muchas veces esta diferencia puede transformarse en jerarquía y si la misma ya existía, el don no hace otra cosa que representarla y legitimarla.

Con lo cual la relación social creada por el don estará expresada en la deuda. El reconocimiento de la misma implica entrar en la lógica de la retribución de dones, en un círculo de relaciones de intercambio en el que están inmersos los actores. Las demostraciones de lealtad son parte de los bienes que circulan en el intercambio.

Al analizar el acto de donar como un encadenamiento de tres obligaciones (dar, recibir y devolver) una de las preguntas que Mauss se hacía era ¿por qué se dona? La respuesta se encontraba en el hecho de que donar, obliga:

[...] tanto negarse a dar, como olvidarse de invitar o negarse a aceptar, equivale a declarar la guerra, pues es negar la alianza y la comunión. Se da porque se está forzado a dar, ya que el donatario goza de una especie de derecho de propiedad sobre todo lo que pertenece al donante. Esta propiedad se manifiesta y se concibe como una especie de lazo espiritual (1979:169-170).

Ahora bien, Mauss también -y fundamentalmente- se preguntaba por la obligación de devolver. Para ello apelaba -recurriendo al derecho maorí- a la existencia de un espíritu de la cosa que obliga a que ésta vuelva a su donante, "el regalo recibido, cambiado y obligado no es algo inerte. Aunque el donante lo abandone, le pertenece siempre. Tiene fuerza sobre el beneficiario del mismo modo que el propietario la tiene sobre el ladrón [...] el hau acompaña a la cosa, quien quiera que sea su detentador" $(1979: 167)^{22}$. Ahora bien, si partimos de la idea de que las relaciones sociales implican derechos y obligaciones y que el intercambio es el modo en el que se expresan las mismas, podríamos sostener -al igual que Sigaud- que al faltar a una obligación -la de devolver- se corre el riego de romper el vínculo que

22 Para una clara síntesis de las múltiples discusiones surgidas en torno al lugar otorgado por Mauss a la categoría maorí del hau en su "Ensayo sobre el don", ver Sigaud (1999). 
me une a esa persona, esa "especie de lazo espiritual"23.

Como planteé en párrafos anteriores, los actores, si bien atrapados en la dinámica de esas relaciones, tienen un claro interés en la continuidad de las mismas “[...] el interés de las dos partes en recrear las relaciones de intercambio es la principal garantía del futuro de esas relaciones, más que cualquier tipo de garantía jurídica" (Sigaud, 1996:8, nota al pie 23).

Como plantea Leach (1996), el intercambio de regalos (en el caso planteado aquí se trata de favores, reconocimientos) es en realidad lo que uno ve, lo que en realidad subyace es el sentimiento de deuda, las obligaciones morales. Deuda que actúa como una suerte de "cuenta de crédito que asegura la continuidad de la relación. Existe, pues, una especie de paradoja en que la existencia de la deuda pueda significar no solamente un estado de hostilidad, sino también un estado de dependencia y amistad" (op.cit.:175)

La lectura de las excusaciones permite sacar a la luz aquellas connotaciones morales que funcionan como la argamasa que sostiene las relaciones entre los individuos. Así, aparecen valores morales como la gratitud hacia quien facilitó el ingreso, ascenso u otorgó otro tipo de favor. ("hacia quien posibilitó en gran medida su progreso en la carrera judicial"; "por intermedio de quien logré ingresar a la justicia"; "quien siendo titular de la cátedra (...) me honró al proponerme como adjunto") y su contracara, la vergüenza (olvidar que existe una deuda original). El agradecimiento se expresa a través de la lealtad, la cual aparece a su vez como elemento propio y característico de la amistad y el compañerismo ("me une una relación íntima de amistad y frecuente trato, desde hace veinticinco años aproximadamente, lapso en el cual pude seguir toda su carrera en el poder judicial, quien además en algunos momentos, y cuando más lo necesitaba, me brindó su apoyo espiritual").

Es interesante ver también como la obligación surgida por la deuda (Leach, 1996) ${ }^{24}$ de un pariente es en parte heredada y pasa a formar parte de

23 Con respecto al cumplimiento de las obligaciones por parte de los individuos que están trabados en una relación de intercambio, Leach sostiene que “(...) la tradición establece las normas de lo que es correcto. Pero el principio de sustitución hace posible que cualquier hombre evite cumplir la letra de sus obligaciones, si así lo elige; sin embargo, si un individuo no paga lo adecuado, pierde "cara" (prestigio) y corre el riesgo de una pérdida general de estatus de clase" (1996:170)

24 En su trabajo sobre los kachin, Edmund Leach sostiene que -salvo excepciones- “(...) se considera que las deudas existen entre linajes más bien que 
la propia deuda (“Así, además de la amistad ya existente entre el Dr. Gómez y familiares del declarante-desempeñábase desde tiempo atrás en la secretaría $\mathrm{n}^{\mathrm{o}} 6$ el hermano de mi padre-, se forjó a través de esa dilatada relación funcional una amistad que puedo calificar como íntima (...) además de lo cual existe de parte de quien ahora debe decidir el natural agradecimiento hacia quien posibilitó en gran medida su progreso en la carrera judicial"). Deuda que se traduce - un vez más- en expresión de un vínculo.

Los actores recurren al relato de sus propias carreras judiciales, para dar cuenta de las relaciones consideradas "inhabilitantes" y es en ellas donde se pueden detectar lealtades, pertenencias e identidades, así como la creación de obligaciones a partir de los "favores" donados. Los verbos utilizados para referirse a las relaciones entre los funcionarios -"me une", "le debo", "me honró"- y la calificación de esas relaciones -"de quien soy discípulo", "por intermedio de quien logré ingresar"-, permiten descubrir el tipo de lazos que se establecen entre los miembros de la "familia judicial", ya sean éstos de horizontalidad (amistad, camaradería, compañerismo) o verticalidad (sea ésta ascendente o descendente).

En síntesis, pensar en términos de intereses y dependencias recíprocas $^{25}$ entre los socios de los intercambios sociales, permite romper con las lecturas que ven estas relaciones como la realización mecánica del principio de reciprocidad (Sigaud, 1996). De esta manera podemos reconocer el carácter dual de la deuda o, como plantearía Leach, la flexibilidad de un sistema que en apariencia se muestra rígido: "Cualquier persona que recibe un regalo se ve por eso colocado en deuda con el dador. Durante algún tiempo el receptor goza de la deuda (la tiene, la bebe: lu), pero el dador es

entre individuos. Cualquier deuda sin pagar puede traspasarse de generación en generación" (1996:175). Con respecto al intercambio entre grupos recordemos el planteo de Mauss cuando sostiene que “(...) no son los individuos, sino las colectividades las que se obligan mutuamente, las que cambian y contratan; las personas que están presentes en el contrato son personas morales: clanes, tribus, familias, que se enfrentan y se oponen, ya sea en grupos que se encuentren en el lugar del contrato o representados por medio de sus jefes o por ambos sistemas" (1979:160-161)

25 No debemos olvidar que ese acto supuestamente desinteresado de donar pero sin embargo "obligatorio e interesado" (Mauss, op.cit) funciona para quien dona como fuente de prestigio "(...) el poseedor de objetos valiosos gana mérito y prestigio fundamentalmente gracias a la publicidad que obtiene desembarazándose de ellos" (Leach, op.cit.:163) 
el propietario de la deuda (la gobierna: madu). Por tanto, paradójicamente, aunque el individuo de alto estatus se define como el que recibe regalos (v.g., "jefe comedor de muslos"), constantemente está sometido a la coacción social de dar más de lo que recibe. De otra manera será tenido por tacaño y un individuo corre el riesgo de perder su estatus" (op.cit.:184) ${ }^{26}$

\section{Conclusiones}

Las relaciones y obligaciones sociales de las que he intentado dar cuenta a lo largo del artículo están inscriptas en una configuración sociohistórica determinada. Como planteé al comienzo, el hecho de que la causa de la morgue judicial se haya tramitado hacia fines de la dictadura militar y comienzos de la democracia, implica trabajar con un momento bisagra, en el que la situación político-institucional se presenta plagada de incertidumbres $\mathrm{y}$ reacomodamientos. Es un momento fundamental para pagar parte de las deudas $^{27}$ y generar otras nuevas abonando estas dependencias recíprocas o "redes de interdependencia" (Elías, 1996) en las que están insertos los actores.

Pensar en términos de configuraciones permite indagar acerca de la autonomía y la dependencia relativa de los hombres en sus relaciones ${ }^{28}$, evitando, de esta manera, aislar las conductas al analizarlas dentro de sus cadenas de interdependencias recíprocas. Así, como plantea Elías, figuras que se "destacan" en sus acciones y obras personales, pueden tener un campo de acción mucho más amplio gracias a la posición social ocupada dentro del sistema de poder. En otras palabras, es necesario analizar la relación

$26 \quad$ Sobe el interés en el intercambio y la importancia de la generosidad como fuente de honor y prestigio, ver también Malinowski, Bronislaw: Los argonautas del Pacifico Occidental

27 Saldar la deuda completamente implicaría cerrar la relación. Los presentes son formas parciales de saldar la deuda, de entretener.

28 "Mientras un hombre vive y está sano posee, aunque sea prisionero o esclavo, una cierta autonomía, un campo de acción dentro del cual puede y debe tomar decisiones. Por el contrario, aun la autonomía, aun el campo de acción del rey más poderoso tiene límites fijos; está implicado en una red de dependencias cuya estructura puede definirse con gran exactitud (...) Sobre esta base, se puede mostrar fácilmente que al ampliarse el campo de acción de un determinado individuo o de un grupo determinado de individuos, puede quedar reducida la "libertad" de otros individuos" (Elías, 1996:48) 
establecida entre persona individual y posición social. Por ello en el análisis del funcionamiento del poder judicial durante la última dictadura es preciso considerar las relaciones propias del desempeño funcional de los individuos (aquellas que están sujetas al escalafón y que establecen las jerarquías internas del poder judicial) atravesadas por todas esas "otras" relaciones surgidas de la vida social ampliada de los sujetos, que se encuentran regidas por "otras normas" que no son las jurídicas. Todo esto en el contexto puntual de una dictadura, donde los límites y elasticidades para la acción personal presentan más limitaciones. No estamos hablando de hombres sueltos sino de sujetos que pertenecen a determinados grupos y que poseen intereses e identidades compartidas. Las redes de interdependencia otorgan una fuerza particular a las acciones de los sujetos $\mathrm{y}$, a su vez, les marcan límites estrictos que "como los de la elasticidad de un muelle de acero, se hacen sentir tanto más fuertemente, cuanto su detentor, por la orientación individual de su conducta, pone más en tensión y a prueba la elasticidad de su posición social" (Elías, 1996:33).

Entonces hablar en términos de configuraciones sociales en conjunción con la lógica de los intereses que sustentan los individuos, permite dar cuenta de las estrategias desplegadas por lo sujetos en el manejo de la "deuda", estrategias que, como se sostuvo en párrafos anteriores, permiten flexibilizar el mundo social del que forman parte. Ahora bien, no se trata sólo de las estrategias desarrolladas por los individuos para la devolución de la deuda sino de la generación de la misma como una estrategia de poder que permite la creación de aliados.

Otro elemento que es necesario incorporar al análisis es la dimensión temporal. En las excusaciones se puede observar la recurrente mención del tiempo en la descripción de las relaciones entre los individuos ("me une una larga amistad que data de los comienzos de la década de 1960"; "cabe destacar que existe con ambos una relación de amistad, que se manifiesta a través de la frecuencia en el trato que mantengo con ellos desde aproximadamente quince años"; "a quien me une una amistad íntima, prolongada e ininterrumpida desde el año 1956"). Bourdieu plantea que el intervalo temporal ${ }^{29}$ entre el obsequio y el contraobsequio cumple un papel determinante, ya que "(...) prácticamente en todas las sociedades, está tácitamente admitido que no se devuelve de inmediato lo que se ha recibido -lo que equivaldría a rechazarlo." (2002:161). Esto permite que dos actos perfectamente simétricos (dar 29 El planteo de que la devolución del presente no puede ser inmediata, debe estar diferida en el tiempo ya fue planteada por Malinowski (2001) y Leach (1996). 
y devolver) parecieran actos únicos, no vinculados. De esta manera se colabora con el ocultamiento del interés que en realidad existe en ese acto supuestamente generoso y desinteresado que es el dar, ya que si se rompiese ese acuerdo tácito entre los que participan en el juego de los intercambios se correría el riesgo de acabar con el juego. Por otra parte, la incorporación de la dimensión temporal genera incertidumbre (siempre existe el riesgo -por nimio que éste sea- de que el don no sea devuelto) y la posibilidad de que los individuos desarrollen estrategias para garantizar el retorno del presente. Y es a través del desarrollo de diferentes estrategias que los actores manipulan las reglas.

En este sentido, y para finalizar, me gustaría destacar el caso de Oliveri - el juez que "corta" la cadena de excusaciones-, ya que es quien echa luz sobre los intereses que permiten que se produzca ese juego de los intercambios, poniendo en discusión el juego mismo. Cuando Oliveri se refiere a los excusados como "conformantes de una verdadera "familia judicial", fruto de una imbricada red de relaciones funcionales y -mayoritariamenteextrajudiciales que liga a las magistrados y ex magistrados del fuero, desde los más antiguos camaristas hasta los flamantes colegas del suscripto (...)", se coloca en una postura más jurídica y universalista que sus pares, haciendo caso omiso de las "otras" normas, a las que reconoce pero a las que sin embargo coloca en un segundo plano. En otras palabras, mediante la resolución por la que rechaza las excusaciones de sus pares, Oliveri admite la existencia de esas relaciones que están por fuera de las relaciones funcionales, reconoce las obligaciones que esos vínculos conllevan pero las rechaza como argumento, restituyéndole peso a la normativa jurídica. Así, a través de ese procedimiento produce una doble operación en la que, reconociendo las relaciones y obligaciones de los otros pero invalidándolas como argumento, se libra de explicitar sus propias relaciones y obligaciones.

Es importante destacar que en el momento en el que se produce este conflicto, el hecho de haber develado la existencia de esas otras relaciones fue visto y tomado por determinados sectores -sobre todo aquellos vinculados a los organismos de derechos humanos- como un acto de denuncia que ponía en evidencia la "trenza en la justicia". Se podría arriesgar que si el intercambio de favores opera como una forma de crear vínculos y, por lo tanto, de generar aliados, la resolución de Oliveri lo coloca integrando un sector que irá cobrando fuerza en las nuevas configuraciones que se comenzaban a delinear en la justicia, con la vuelta a un estado democrático. 


\section{Bibliografía}

BOURDIEU, Pierre: Razones prácticas. Barcelona, Anagrama, 2002.

ELÍAS, Norbert: La sociedad cortesana. México, Ediciones del FCE, 1996.

LEACH; Edmund: Sistemas políticos de la Alta Birmania. Barcelona, Anagrama, 1996.

MALINOWSKI, Bronislaw: Los argonautas del Pacífico Occidental. Barcelona, Península, 2001.

MAUSS, Marcel: "Ensayo sobre los dones. Motivo y forma del cambio en las sociedades primitivas". En: Sociología y Antropología. Ed. Tecnos, 1979.

SARRABAYROUSE OLIVEIRA, María José: Cuaderno $\mathrm{n}^{\circ}$ 4. Memoria y dictadura "Poder judicial y dictadura. El caso de la morgue judicial". Facultad de Filosofía y Letras y Defensoría del Pueblo de la Ciudad de Buenos Aires, 2003.

coexistentes: Reglas universales y relaciones personales". En: Sofía Tiscornia (comp.): Burocracias y violencia. Ensayos sobre Antropología Jurídica. Buenos Aires. Antropofagia, 2004.

SIGAUD, Lygia: "Armadilhas da honra e do perdão: Usos sociais do direito na mata pernambucana". Em: Maná, Estudos de Antropologia Social. Vol. 10 (1) Río de Janeiro, 2004.

“As vicissitudes do 'Ensaio sobre o dom'”. Em: Maná, Estudos de Antropologia Social. Vol. 5 (2), Río de Janeiro, 1999.

_."Direito e coerção moral no mundo dos engenhos". Em: Estudos históricos, Vol. 9 nº 18, 1996. 